\title{
The Effect of Organizational Communication Media on Organizational Culture and Performance: An Agent-Based Simulation Model
}

\author{
ENRIQUE CANESSA \\ Universidad “Adolfo Ibañez”, Faculty of Science and Technology, Balmaceda 1620, Viña del Mar, Chile \\ email: ecanessa@uai.cl or ecanessa@umich.edu
}

RICK L. RIOLO

University of Michigan, Center for the Study of Complex Systems, 4477 Randall Lab., Ann Arbor,

MI 48109-1120, USA

email: rlriolo@umich.edu

\begin{abstract}
This paper examines the mutual relationship between the communication richness of media used for conducting organizational communication and organizational culture. The richness of the media influences how well the organization might maintain its culture. On the other hand, a strong organizational culture allows a more effective use of the media by providing members with some of the necessary common ground to better understand the information exchanged. These relationships are investigated using an agent-based simulation model (ABM). Our ABM incorporates many partial theories into a coherent and fully defined model, which helps formalize and integrate those theories. Our model allows us to analyze non-linearities and interaction effects, which are difficult to investigate using other techniques. Additionally, the ABM allows us to investigate the dynamics of the phenomenon and generate hypotheses that could then be tested using empirical studies. Given the substantial resources necessary to conduct empirical studies, we think that the present ABM is valuable in helping guide data collection efforts. In this paper, we present results that show that organizational culture can influence the effectiveness of the media used for organizational communication and that a high media richness can help maintain and stabilize a culture. The effect of media richness on organizational culture depends on the initial strength of the culture. In general, for a given richness of the media, an initially strong culture stabilizes faster and becomes stronger through time than an initially weak culture. Additionally, the model suggests that a stable network of contacts among agents fosters a high achievement of organizational tasks. Conversely, when agents are forced to establish contacts with agents outside the usual network for doing their work, the accomplishment of tasks decreases.
\end{abstract}

Keywords: agent-based modeling, organizational culture, organizational communication

\section{Introduction}

Organizations rely on information for making decisions, controlling tasks and coordinating interrelated activities (Thompson, 1967; Weick, 1979; Huber, 1982; Stinchcombe, 1990). To serve those purposes, information must be transferred among members of an organization, e.g., by face-to-face meetings, telephone conversations, memoranda and other media provided in general by Information Technology (IT), such as Computer Mediated 
Communication (CMC) (William, 1977). Depending on the geographical and/or time separation among members of an organization, they will need to use different media for communicating. For example, if members are physically separated, they might exchange information through an electronic mail system. Many studies have suggested that those types of systems have the potential to enhance the flow of information among members of an organization (Gurbaxani and Wang, 1991; Fulk and DeSanctis, 1995). However, research aimed at analyzing the effective use of different communication systems in organizations has arrived at different conclusions.

One of the most widely known and used theories applied to studying the effective use of different communication media is Information Richness Theory (IRT) (Daft and Lengel, 1986; Olson and Olson, 2000). IRT states that the communication richness of a medium explains why it is more or less effective. Communication richness refers to the ability of a communication system to transfer enough cues so that individuals can reach an understanding within a short time interval. For IRT, the effectiveness of the information exchange is related to establishing an understanding of the ideas exchanged between sender and receiver, overcoming the problems of equivocality and ambiguity that might exist. Media high in richness allow the fast, unambiguous and unequivocal exchange of information. For IRT, face-to-face communication is the richest media because it provides immediate feedback so that interpretation can be checked. In addition, face-to-face communication permits the exchange of multiple cues through body language, tone of voice and natural language (Sproull and Kiesler, 1986). On the other extreme, media such as impersonal written documents provide fewer cues and restricted feedback. Thus, these media are low in richness and inappropriate for resolving equivocal issues.

On the other hand, other studies have shown that organizational members could effectively communicate under ambiguous conditions with "lean" media, contrary to IRT's prediction that "rich" media would be required (Lee, 1994; Ngwenyama and Lee, 1997). The main idea of these studies is that the richness of any communication medium changes according to the organizational context in which it is used: The person who sends a message and the one who receives it are part of an organizational context, so they not only derive the meaning of the message from the information provided by the message, but also interpret it taking into account other information they have at their disposal, such as knowledge of the other person, of the situation at hand and of the organization. The individuals who are communicating are an active part of the communication process and not mere passive subjects who restrict their attention to the bare facts reflected in the message.

As one can see, IRT-based studies focus mainly on the intrinsic characteristics of the communication medium and analyze them independently of the individuals and organizational context. On the other hand, for other studies, the attributes of a communication medium are dependent on both the intrinsic and extrinsic characteristics of the medium. Those extrinsic characteristics originate from the individuals who use it and the organizational context. Thus, we can distinguish between an intrinsic and extrinsic richness for a medium.

In line with the drawbacks of early research on communication effectiveness discussed above, recent studies have investigated the topic using a more comprehensive view of the phenomenon. Topics such as organization design, group structure, social interaction 
and task characteristics have been incorporated in studies of communication media effectiveness (Baltes et al., 2002; Cornelius and Boos, 2003; Potter and Balthazard, 2002; Alge et al., 2003). These studies provide a thorough analysis of many important aspects to consider when investigating the effectiveness of organizational communication media for accomplishing different tasks. However, one aspect that has not generated much attention is organizational culture itself. Although implicitly stated in some studies, few papers have explicitly incorporated organizational culture in the analysis of organizational communication effectiveness. One study that explicitly included organizational culture focused on only two specific dimensions of a culture: task and people orientation (Kanungo, 1998). This study mainly investigated the link between computer mediated communication use and user satisfaction with that system. No overall treatment of organizational culture and organizational communication via different media was attempted. Therefore, we think that exploring the link between culture and communication effectiveness of different media can help add a new perspective to existing research. Moreover, we think that, as pointed out before, the extrinsic characteristics of a media emanating from the organizational context, is related to culture. We will further elaborate on the relationship between organizational culture and the communication process in the next section.

In this paper we build an agent-based model (ABM) to explore the relationship between communication media richness, organizational communication and organizational culture. We think that ABM is a useful tool because modeling human behavior potentially involves taking into account many factors and partial theories, which can be integrated within an ABM to see how well they hold together (Jacobsen and Bronson, 1997). Using ABM one can integrate many partial theories or results of studies related to a phenomenon or system into a coherent synthesis that can better describe the phenomenon or system (Anderson, 1999). Additionally, it is easier to explore the dynamics of a phenomenon with an ABM, since one can obtain as much longitudinal data as needed to characterize the development of the system through time. Since sociological phenomena commonly exhibit non-linearities and interaction effects (Weick, 1979), we think that developing an ABM to investigate the present topic will prove to be useful. Our own experience in investigating the use of IT systems in organizations using survey research and ABM supports that point of view (Canessa, 2002).

The rest of the paper is organized as follows. Section 2 develops some hypotheses that postulate that organizational culture strength may increase the effectiveness of communication media, and that media richness may impact the strength of a culture and its maintenance. Section 2 also presents some hypotheses that state a possible beneficial impact of organizational culture strength and media richness on some measures of organizational effectiveness. Next, Section 3 presents an agent-based simulation model of the phenomenon, and Section 4 describes the results of virtual experiments conducted using the model. Additionally, Section 4 presents some unexpected and interesting results derived from the outcomes of the simulation runs. Section 5 discusses the findings of this paper. Then, Section 6 discusses the limitations of the ABM and of the present study. Section 7 suggests some additional work that may be done to further analyze the dynamics of the model, and the paper ends with a summary of the most important points presented in the paper. 


\section{Hypotheses}

This section develops some hypotheses that relate organizational culture, communication richness and some measures of organizational performance. Although these hypotheses plausibly follow from theory, because of non-linear interactions among variables and the general complexity of the phenomenon, it is not possible to determine a-priori that a particular formal model would generate results that would support those propositions. And in fact, the model we present in Section 3 generates many surprising results, as described in this paper and in Canessa, 2002. This situation agrees with similar experiences reported in other studies (Axelrod, 1997a,b).

\subsection{Effect of Organizational Culture Strength on Communication Richness}

As discussed in the introduction to the paper, there is evidence that supports the view that media richness is both an intrinsic and extrinsic characteristic of a communication medium. The extrinsic communication richness originates from the individuals who use the medium and the organizational context. One way to succinctly incorporate organizational context into the analysis of any communication system is in terms of organizational culture (Schein, 1985; Chatman, 1988; Lea et al., 1995; Zack and McKenney, 1995; O'Reilly and Chatman, 1996). One definition of organizational culture states that it is "a pattern of basic assumptions, invented, discovered or developed by a given group, as it learns to cope with its problems of external adaptation and internal integration, that has worked well enough to be considered valid and therefore is to be taught to new members as the correct way to perceive, think, and feel in relation to those problems" (Schein, 1990). This definition of organizational culture (OC) suggests that $\mathrm{OC}$ will contribute to enhancing the possibility of reaching a mutual understanding when members of the organization communicate. Common assumptions tend to homogenize how members handle their work-related problems, thereby contributing to a common understanding, which will facilitate communication, especially when using low to medium richness media (Clark, 1996; Chin et al., 2002; Cornelius and Boos, 2003). Thus, the intrinsic low richness of lean media will be supplemented by this extrinsic richness provided by organizational culture. This beneficial effect of organizational culture will depend on how widespread and strongly members of the organization hold the assumptions embedded in the culture. If only a few members hold the assumptions or if individuals have different assumptions, then the homogenizing effect of culture will be confined to a small group of individuals and/or will be weak. The contrary will happen if the assumptions are widely held among individuals. A variable that represents this attribute of organizational culture is its strength (Denison, 1990). These points can be summarized in the following hypothesis:

H1. The stronger the organizational culture, the higher the communication richness of the communication system will be.

\subsection{Effect of Communication Richness on Organizational Culture Strength}

An organization develops its culture by arriving at a shared understanding (Schein, 1985; Chatman, 1988). Shared understanding means that members of the organization recognize 
a particular feeling, experience or activity as common and are willing to adhere to a set of beliefs, values and norms in acting. Arriving at a shared understanding presumes that members have access to a common communication system, in which signals mean the same thing to each member (Schein, 1985). Only by exchanging their ideas can members form the culture. Thus, if the intrinsic communication richness of the medium that members use is high, then the medium will effectively contribute to creating the overall shared meaning (Kiesler, 1986). This will help create a strong culture (Chatman, 1988; Denison, 1990). It follows that the richer the communication system, the stronger the culture might be.

Similarly, a culture must be maintained. This entails that organizational members continue to adhere to the culture as long as they belong to the organization and that new members are properly socialized when joining the organization (Chatman, 1988). The maintenance process is similar to the one explained in the previous paragraph, so that the richer the communication system, the better new members might be socialized.

In summary, the communication richness of the system will influence the creation and maintenance of the organizational culture. This argument leads to the next hypothesis:

H2. The richer the communication system used in an organization, all other factors being equal, the stronger the organizational culture will be.

\subsection{Effect of the Initial Strength of Organizational Culture on the Stabilization Time of the Culture}

If the initial strength of the organizational culture is high, then members of the organization will have somewhat similar values, beliefs and assumptions. That common ground provided by a strong culture will facilitate the communication process. Thus, it will take the members a shorter time to reach a consensus than if the initial culture is weak. Thus, one can state the following hypothesis:

H3. The stronger the initial organizational culture, the faster the culture will stabilize.

\subsection{Effect of Organizational Culture Strength and Communication Richness on Some Measures of Organizational Effectiveness}

The previous subsections hypothesized possible relationships between culture and communication richness. From a practical point of view, it is also interesting to see whether the mutually beneficial effects of a strong organizational culture and high communication richness might be reflected in the effectiveness of the organization.

Some case-based and empirical studies have suggested that a strong organizational culture can enhance the performance of an organization (Chatman, 1988; Denison, 1990; Smith and Rupp, 2002; Chin et al., 2002). The main argument is that a strong culture provides members a sense of commitment to the organization, helps align the individual goals to organization goals and establishes a common ground that facilitates work among employees. Those 
beneficial effects might be reflected in reducing the time required to complete organizational tasks:

H4. The stronger the organizational culture, the shorter the task-completion time.

Additionally, since high communication richness might help establish and maintain a strong culture, one can postulate that it will also have a positive effect on task-completion time. The following hypothesis reflects this argument:

H5. The higher the communication richness, the shorter the task-completion time.

\section{The Model}

In this section we describe a model that implements the conceptual ideas and mechanisms from the theory outlined in Section 1 that bear on the hypotheses described in Section 2. There are many ways to implement those basic ideas. The present model is an attempt at a fairly simple implementation that captures the key mechanisms believed to be the most relevant. This agent-based simulation model represents two related phenomena. The first one corresponds to the organizational communication aspect that takes place in an organization among members for accomplishing their tasks. The second phenomenon is the creation, evolution and maintenance of an organizational culture.

In short, the model consists of a given number of agents who belong to different groups of an organization. The organization assigns a task to each member. To accomplish its task, an agent must successfully communicate with a given number of other agents in a given sequence. Each agent has a culture (i.e., a set of cultural attributes) represented by an array of numbers. Each number represents a different trait of the culture. The more similar the culture of the sender and receiver of the message, the more successfully they can communicate. While communicating, the sender and receiver change their own culture, so that they become more similar to each other. The communication richness of the media agents use for communicating affects the magnitude of the change in culture: the richer the medium, the bigger the change in culture. Every time an agent completes a task, the model assigns to it a new one.

The following subsections describe the details of the model that are important for understanding the experiments carried out to test the hypotheses listed in Section 2. For full details and for additional hypotheses and virtual experiments see Canessa (2002). We should note that in the subsections that follow, we give some values for some of the parameters of the model, without explaining the reason for having selected those specific values. We will explain the reasons for those choices in Section 6, where we discuss the limitations of this study.

\subsection{Organizational and Communicational Structure}

The model assumes that an organization is a collection of groups of people who pursue some common objectives (Hunt, 1972). The groups represent the departments, sections or 
whatever organizational divisions the firm has established. To reflect the relative difference in power position among members of a firm (Salancik and Pfeffer, 1974), the model assigns to each agent a corresponding number that represents its status.

The model assumes that members of a group can freely communicate. This reflects the idea that a firm sensibly defines its organization, assigning its members to groups to facilitate the work employees must do by putting together members who must frequently communicate (Thompson, 1967; Stinchcombe, 1990). In the case of inter-group communication, the model assumes that only some members of a group may directly communicate with members of other groups. This reflects the idea that the majority of the members belonging to a group are supposed to carry out their activities within the group and only a few members need to participate in activities with members of other groups (Thompson, 1967; Stinchcombe, 1990). Since we have agents that can communicate outside their groups and others that cannot, the following situations might arise:

(a) An agent needs to exchange information with another agent that belongs to the same group. In this case, the sender directly sends a message to the receiver. The receiver sends its answer back directly to the sender.

(b) An agent needs to communicate with another agent that belongs to a different group. If the sender has permission to communicate with members of other groups and the corresponding receiver is also allowed to communicate with members of other groups, then the sender sends its message directly to the receiver. The receiver sends its answer back directly to the sender.

(c) The sender does not have permission to exchange information with members of other groups, but the agent the sender wants to communicate with does have this permission. In this case, the sender randomly selects one of the members of its group who is allowed to communicate with members of other groups. The selected agent relays the sender's message to the member of the other group. The reply to the sender's message follows the same route back from receiver to original sender: the receiver sends its reply to the member of the group from whom it received the message and this agent finally sends the reply to the original sender.

(d) The sender and receiver do not have permission to communicate outside their respective groups. In this case, the sender randomly selects one of the members of its group who is allowed to communicate with members of other groups. This member relays the message to a randomly selected member of the corresponding group who can exchange information with outside members. Finally, this agent relays the message to the receiver. The answer to the message follows the same route back from receiver to sender.

The capability of members to communicate outside their groups might influence their status. Since members who have a broader communication network have more influence in an organization, the status of the agents that can communicate outside their own group will be higher than the status of those agents that cannot (Schwartz and Jacobson, 1977; Krackhardt and Hanson, 1993). For this study we set the status of agents that are not allowed to communicate outside their group to one and the status of agents that may communicate outside their group to two. 


\subsection{Task Assignment}

The organization assigns to each agent a task to complete. Each task consists of a given number of contacts, which we call steps, that the agent must make with other members in order to complete the task. In this study we use tasks consisting of 10, 20, 30 and 40 steps (see Table 1 and Section 4.2). Some steps are sequential and thus the agent must wait until it receives a reply from another agent before advancing to the next step. On the other hand, some steps are non-sequential and the agent can work on the next step while waiting for the answer. The organization assigns sequential task steps with probability 0.5 .

If an agent is authorized to communicate outside its group, with probability 0.6 the organization assigns to it steps that involve contacting agents in other groups; if an agent is not authorized to communicate outside its group, that probability is 0.3 . We assign a bigger probability of having to communicate outside the group to agents which are allowed to do so, because we assume that the organization sensibly gives this permission to agents which need to communicate outside the group. On the other hand, if the organizations believes that some agents don't need to communicate outside their group, then it is less likely to assign them tasks that require inter-group communication.

Each time an agent completes a task the organization assigns a new one to it. With probability 0.5 the organization changes the identity of the agents involved in completing the new task and/or the sequence in which the contacts must be made. This reflects the stability of the working environment of the organization. The lower the probability of changing contacts, the more stable the environment.

\subsection{Completion of Tasks}

The following are the rules that agents observe when carrying out their assigned tasks:

(a) An agent works to complete one task at a time.

(b) The number of steps of a task that an agent can perform in a simulation step is equal to the number of messages an agent can answer. Values of 10, 20, 30 and 40 were used in the virtual experiments, as described in Section 4.

(c) An agent processes the messages that belong to its own task first. After that, if the number of already processed messages is smaller than the maximum number of messages the agent can process, then it processes messages that were sent to it from other agents. The order in which the agent processes those messages is dictated by the status of the senders and their arrival time (FIFO). Each agent selects the messages received from the highest status agents and process them in FIFO order. If the number of processed messages so far is less than the number of messages the agent can process, then the agent selects the messages that have the second highest status and answer them. This process continues until no more messages remain in the agent's queue or the number of answered messages equals the number of messages the agent can process per time step. 


\subsection{Organizational Culture and Its Effect on Communication Effectiveness}

Each agent's culture (i.e., set of cultural attributes) is represented by a list of numbers, one value for each cultural dimension (Axelrod, 1997a). For the results reported here the number of dimensions is 10 (but see section 6 for a discussion of results for 20 dimensions). Thus the overall organizational culture is represented by a matrix $T(i, j)$ where the $i, j$-th entry is agent $i$ 's value for dimension $j$. The initial values for each dimension of each agent are sampled from a normal distribution with mean zero and a given variance. This variance defines the starting variability of the organizational culture and thus, the corresponding initial cultural strength. A strong culture is one in which the members of an organization have almost identical values for each dimension. Thus, the larger the variance is, the weaker the initial culture.

Communication effectiveness (CE) is defined as the probability that two agents can communicate without problems. $\mathrm{CE}$ is a function of the difference in culture between two agents, based on the sum of the absolute value of the differences in values between corresponding dimensions for the two agents. A sigmoid curve is used to calculate CE:

$$
\mathrm{CE}_{j k}=\frac{1}{1+e^{\left(\sum_{i=1}^{N}\left|T_{i j}-T_{i k}\right|\right) \alpha-\beta}}
$$

where $T_{i j}$ is the $i$ th dimension of the culture of agent " $j$ " and $T_{i k}$ is the $i$ th dimension of the culture of agent " $k$ " and $N$ equals the number of cultural dimensions. The constants $\alpha$ and $\beta$ adjust the shape of the sigmoid curve. In this study, $\alpha$ was set to 0.25 and $\beta$ to 5.0. We will discuss the meaning of the parameters $\alpha$ and $\beta$ and the values we used in Section 6.

Communication effectiveness takes a value very close to one (provided we set a sufficiently large $\beta$ ) when there is a perfect match between the cultures of both agents; $\mathrm{CE}$ decreases toward zero as the difference between the cultures of both agents increases. The value of $\mathrm{CE}$ between two agents specifies the probability that the receiver of a message understands it. If the receiver understands the message, then it processes the message. However, if the receiver does not understand the message, then the receiver replies with a clarification message. The sender of the first message responds to this clarification message. Upon receiving the answer to the clarification message, the receiver decides if it now understands the new message. This process continues until the receiver understands the message or the receiver or sender quits sending/answering clarification messages. The receiver or sender quits sending/answering clarification messages when the number of clarification messages exceeds three. If the sender quits answering or the receiver notifies the sender that it quit sending clarification messages, then the sender selects a new receiver for the original message. This change of receiver occurs only once. If after changing receiver, the original message is still not understood, then the communication fails, in which case the organization discontinues the corresponding task and assigns a new task to the agent.

As we will explain in the next subsection, the cultures of sender and receiver become more similar every time they communicate, which increases CE and the probability that the receiver will understand the message of the sender. Thus, clarification messages improve understanding through that mechanism. 


\subsection{Communication Richness and Organizational Culture Change}

As discussed in Sections 1 and 2, different communication channels exhibit varying capacities for transmitting different types of cues, which we called the intrinsic communication richness. This means that different communication channels are more or less apt to transmit different dimensions of a culture. Therefore, when agents communicate using a channel, this channel will allow them to transfer some dimensions of their culture and will block the transfer of other dimensions. Thus, one can assume that the only dimensions of a culture that could change between agents are the ones that the communication channel transmits, called the "visible dimensions". The model allows establishing the number of visible dimensions for communications among agents that belong to the same group (intra-group communication) and for communications among agents that belong to different groups (inter-group communication). The reason for distinguishing between the richness of intra and inter-group communication channels is that the members who belong to the same group will have more opportunities to communicate through rich channels (for example face-to-face meetings) than members who belong to different groups (Olson and Olson, 2000).

The organizational culture change between agents takes place every time two agents communicate. The receiver of the message will change its culture toward the one of the sender in an amount proportional to the communication effectiveness and the difference in status between both of them. Assuming that agents " $s$ " (sender) and " $r$ " (receiver) communicate, agent " $r$ " culture will change according to the following formula:

$$
\begin{aligned}
& \forall \text { VisibleDimensions " } i \text { " between agent "s" and " } r \text { ": } \\
& T_{t, i, r}=T_{t-1, i, r}+C E_{s r}\left(T_{t-1, i, s}-T_{t-1, i, r}\right) \frac{\text { Status }_{s}}{\text { Status }_{s}+\text { Status }_{r}}
\end{aligned}
$$

where $T_{t, i, r}$ is the value of dimension $i$ at time $t$ for agent $r$. The quotient of the statuses of the agents represents the asymmetrical nature of the influence that persons of different status can exert on each other (Salancik and Pfeffer, 1974). The bigger the difference in status between two persons, the higher the influence the person of higher status can exert on the person of lower status and, the lower the influence the person of lower status can exert on the person of higher status.

The effect of CE on the magnitude of the cultural change reflects the influence one person might have on another's culture if they can understand each other (Axelrod, 1997a). The model assumes that the change in organizational culture is unidirectional; that is the sender influences the culture of the receiver and not vice versa. Since the receiver acts as sender when responding to the message and the original sender acts as receiver, the effect becomes bi-directional but not synchronous.

\subsection{Sequencing of Events and Updating of the Model}

The initialization of the simulation involves the creation of the specified number of groups and agents per group, the assignment of characteristics to each agent (whether it is or not allowed to communicate outside its group; a status equal to two if an agent is allowed to 
communicate outside its group and a status equal to one if it may not do so; and the message processing capability, which may be $10,20,30$ or 40 messages per time step, see Table 1 and Section 4.2) and the creation of an initial task for each agent. As already explained, the tasks for each agent may contain 10, 20, 30 or 40 steps, according to the value specified by the researcher. After initialization, the simulation is updated asynchronously (to avoid artifacts-cf. Huberman and Glance, 1993). The updating of the simulation involves the following steps:

(a) Select at random without replacement agent $\mathrm{A}$ from the list of all agents.

(b) Allow A to send messages for its current task.

(c) Process the incoming messages for A and change its organizational culture.

(d) See whether A's task is complete. If the task is complete:

(i) Compute the relevant measures pertaining to the task (see Section 3.7).

(ii) Assign a new task to A.

(e) Repeat actions (a) through (d) until all agents have gone through that process.

(f) Compute the measures and outputs of the model (see Section 3.7).

(g) Repeat actions (a) through (f) for as many simulated time steps as specified.

\subsection{Measures and Outputs of the Model}

The following measures are used for presenting the results of this paper. Note that a "simulation step" consists of one execution of actions (a)-(f) (described above),

(a) Average task-completion time for the organization (ATCTO). For all the completed tasks calculate the time it took to finish those tasks. This time is expressed in number of simulation steps needed to complete the tasks. Using those times, calculate an average time for the entire organization. This time reflects only the time agents spend in communicating. The time an individual will spend in doing the work itself, for example writing a report, is not included. Thus, this measure only assesses how long it takes members to carry out the communicational part of their jobs. If $S_{i}$ is the number of simulated time steps it took to finish task " $i$ ", then we can write:

$$
\text { ATCTO }=\frac{\sum_{i=1}^{\text {all tasks completed }} S_{i}}{\text { Number of tasks completed }}
$$

Note that times to complete tasks are expressed in simulated time steps. Therefore, they are useful in relative comparisons but are meaningless in absolute terms.

(b) Overall organizational culture strength (OOCS) measures the strength of the organizational culture by calculating the variance for each of the dimensions of the culture for 
the entire organization, combining them using the following expression:

$$
\mathrm{OOCS}=\frac{1}{1+\sum_{i=1}^{N} \sigma_{i}^{2}}
$$

where $\sigma_{i}^{2}$ is the variance of cultural dimension $i$ and $N(=10)$ is the number of cultural dimensions. Note that the stronger the culture, the smaller the variation and thus the closer OOCS will be to one. OOCS is calculated every time the model is updated (updated at step $f$, see Section 3.6).

(c) Organizational average culture $(\mathrm{OAC})$ is the average value of the culture computed over all cultural dimensions and agents of the organization $\left(T_{i j}\right)$. If $N(=10)$ is the number of cultural dimensions and TNA is the total number of agents of the organization (240 in this study), then we can write:

$$
\mathrm{OAC}=\frac{\sum_{i=1}^{N} \sum_{j=1}^{\mathrm{TNA}} T_{i, j}}{N \cdot \mathrm{TNA}}
$$

The time series (where time is expressed in simulated time steps) consisting of OAC values calculated at each simulation step will reflect the dynamics of the culture of the entire organization. When this time series remains unchanged, the system will be in equilibrium. The time at which that happens will correspond to the stabilization time of the culture. As explained in Section 4.5, after a sufficiently long simulation time, the culture homogenizes as much as the conditions of the simulation allow. Thus, the stabilization time of the culture is a well-defined measure of how long it takes the system to achieve cultural equilibrium.

(d) Average communication effectiveness for completing tasks for the entire organization (ACETO). The program calculates the communication effectiveness for each assigned task, even if it was not completed. The average CE for a task is calculated as the geometric mean of all the CE's between senders and receivers. For example, if agent 1 needs to communicate with agent 4 and to do so needs to go through agents 2 and 3 for completing the task " $i$ ", then:

$$
\mathrm{CET}_{i}=\left(\mathrm{CE}_{12} \mathrm{CE}_{23} \mathrm{CE}_{34} \mathrm{CE}_{43} \mathrm{CE}_{32} \mathrm{CE}_{21}\right)^{1 / 6}
$$

where $\mathrm{CE}_{12}=\mathrm{CE}$ between agent 1 and $2, \mathrm{CE}_{23}=\mathrm{CE}$ between agent 2 and 3 , and so on. Using the $\mathrm{CET}_{i}$ of all the assigned tasks, the program computes the average:

$$
\mathrm{ACETO}=\frac{\sum_{i=1}^{\text {all task assigned }} \mathrm{CET}_{i}}{\text { Number of tasks assigned }}
$$

This measure reflects how well agents are communicating due to the intrinsic and extrinsic communication richness of the medium. If the intrinsic richness is high (i.e. the communication channel allows the transfer of many cultural dimensions), the culture is able to homogenize well and that increases the similarity among the agents' cultures. 
If the extrinsic richness is high (i.e. the agents' culture is already similar), the difference between the cultures of agents is low. In both cases, the $\mathrm{CET}_{i}$ and ACETO will be high (close to one).

\section{Results}

\subsection{Verification of the Simulation Program}

Before running experiments, we carried out extensive verification of the program. This section briefly describes the process; full details can be found in Canessa (2002). The verification of the model was done using a bottom-up and top-down approach (Sargent, 1988). In the bottom-up approach, one first checks the objects and then the overall model. In the top-down approach, one starts verifying the whole model and traces the discrepancies found down to specific objects. The bottom-up approach was mainly used when creating the agents. Since the behavior of the agents embeds most of the conceptual model, this object was developed step by step, adding more features only after carefully verifying that previous features were correctly functioning. To do so, we used simple test cases, disabled all the random elements of the object and traced the program execution by observing the relevant outputs. In the top-down approach, the simulation model was run using a set of predefined conditions for which one could predict the correct outcomes of the program based on the description of the model. For example, in one such run, no agents were authorized to communicate outside their groups. Under that condition, no task requiring inter-group communication should be completed and each group should develop its own culture. The output of that run showed that was the case.

\subsection{Trial Runs and Virtual Experiments}

After extensively verifying the program, we conducted trial runs in which we analyzed the behavior of the model under seventy-two different conditions. These trials allowed us to gain insights about the model's dynamics and the effect of various combinations of parameters. Additionally, these runs allowed us to do sensitivity analyses of the different parameters of the model that we keep fixed; for example the $\alpha$ and $\beta$ of the sigmoid curve corresponding to the calculation of communication effectiveness (see Section 3.4). Those analyses showed that the results were robust (Canessa, 2002). Section 6 further discusses this issue. Next, taking into account the insights gained, experimental runs were designed for gathering the necessary data to validate the model and test the hypotheses. Table 1 presents the parameters that were changed in each of the experimental runs. As already explained, other parameters were kept fixed. Those fixed parameters entailed that the simulated organization had eight groups, each with thirty agents. Three agents out of the thirty agents that belonged to each group were authorized to communicate outside the group. These agents had a status equal to two, whereas the rest had a status equal to one. The agents that were authorized to communicate outside their groups had a probability of being assigned a task that required contacting agents that belong to other groups equal to 0.6, whereas the rest of the agents had this probability set to 0.3 . This reflects the idea that the majority of the members 
Table 1. Combination of parameters changed for experimental runs.

\begin{tabular}{|c|c|c|}
\hline Parameter & Value & Experimental condition label \\
\hline $\begin{array}{l}\text { Number of processing } \\
\text { messages per time step for } \\
\text { each agent and }\end{array}$ & $\begin{array}{l}10 \\
20 \\
30\end{array}$ & $\begin{array}{l}10 \text {-step task } \\
20 \text {-step task } \\
\text { 30-step task }\end{array}$ \\
\hline $\begin{array}{l}\text { Number of contacts (steps) } \\
\text { per task }\end{array}$ & 40 & 40-step task \\
\hline $\begin{array}{l}\text { Communication channel } \\
\text { intrinsic richness }\end{array}$ & $\begin{array}{l}6 \text { visible cultural dimensions within group } \\
4 \text { visible cultural dimensions between } \\
\text { groups }\end{array}$ & $\begin{array}{l}\text { Low intrinsic communication } \\
\text { richness }\end{array}$ \\
\hline $\begin{array}{l}\text { (number of cultural } \\
\text { dimensions }=10 \text { ) }\end{array}$ & $\begin{array}{l}10 \text { visible cultural dimensions within } \\
\text { group } \\
8 \text { visible cultural dimensions between } \\
\text { groups }\end{array}$ & $\begin{array}{l}\text { High intrinsic communication } \\
\text { richness }\end{array}$ \\
\hline $\begin{array}{l}\text { Initial organizational } \\
\text { culture strength }\end{array}$ & $\begin{array}{l}\text { Variance of normal distribution }=5 \\
\text { Variance of normal distribution }=10\end{array}$ & $\begin{array}{l}\text { Strong initial culture } \\
\text { Weak initial culture }\end{array}$ \\
\hline
\end{tabular}

belonging to a group are supposed to carry out their activities within the group and only a few members need to participate in activities with members of other groups (Thompson, 1967; Stinchcombe, 1990).

The four different numbers of steps per task were matched up with the corresponding number of messages an agent could process per time step; e.g., for a 10-step task, each agent has the capacity to process 10 messages per step. These four pairs of values were combined with the two scenarios for communication richness and for initial strength of organizational culture, for a total of sixteen combinations. Each of these combinations was simulated for 600 time steps and replicated thirty times using different seeds for initializing the random number generators.

\subsection{Validation of the Model}

Validating a model entails making sure that the model adequately represents the phenomenon under study. In general, validating a simulation model involves a minimum of three steps (Sargent, 1988):

(a) Assessing face validity. This step consists in asking people knowledgeable about the phenomenon whether the model and its behavior are reasonable. We elaborated and checked the conceptual description of the model at several points of its development with researchers who have a vast experience in and knowledge of agent-based simulation modeling and its application to analyzing social phenomena.

(b) Assessing the assumptions of the model. This involves checking whether the theories and assumptions embedded in the model are correct. One can see from the description of the model contained in Section 3 that most of the conceptual model is supported by 
previous research that indicates that the model and its assumptions are adequate to the goals of the present study (Canessa, 2002). For further details see Section 6.

(c) Assessing the match between the results of the model and the behavior of the real system. This step entails comparing the data the model generates with data gathered from the real system and checking that the model outputs match the real system to a required degree of accuracy. We conducted a survey-based study that collected data to test several hypotheses regarding the use of CMC and other Computer Information Systems in organizations, including hypotheses similar to the propositions described in Section 2 (Canessa, 2002). We verified that the empirical data supported some of the same hypotheses described in Section 2. For example, the survey-based study showed that a strong organizational culture enhanced the use of CMC. Additionally, we showed that the results of the model were consistent with the findings of other empirical studies. For example, the results of a study found that the performance of people who worked on a common task, exchanging information through different media, increased as the richness of the media increased (Valacich et al., 1994). As we will see, this finding is consistent with the support that the simulation model lends to hypotheses H4 and H5 (a strong culture and high communication richness can shorten task-completion time). For further details see Canessa (2002).

\subsection{Hypotheses Testing}

This subsection presents the results of the experimental runs and the tests of the hypotheses. Additionally, other interesting and unanticipated results related to some hypotheses are presented. To facilitate the reference to the hypotheses, each is presented at the beginning of the paragraphs devoted to explaining the corresponding results. Tables 2 and 3 show the data gathered from the runs, which we will use in testing the hypotheses and making other analyses. Specifically, Table 2 presents the organizational culture strength (OOCS) and its standard deviation computed over the thirty replications using the last sixty data points of each run, where the system was in equilibrium.

Table 3 presents the overall organizational communication richness and its standard deviation computed under the same conditions.

This overall organizational communication richness corresponds to the average communication effectiveness (ACETO), which encompasses both the intrinsic richness that does not change (due to the established number of visible cultural dimensions between and within groups) and the extrinsic richness, which changes. Extrinsic richness changes because the culture of agents becomes more similar as the simulation advances.

H1. The stronger the organizational culture, the higher the communication richness of the communication system will be.

If hypothesis $\mathrm{H} 1$ is true, we would expect to see that the higher the value of OOCS in Table 2, the higher the corresponding value of ACETO in Table 3 would be. Figure 1 shows 
Table 2. Organizational culture strength for the 16 experimental conditions.

\begin{tabular}{|c|c|c|c|c|}
\hline & \multicolumn{2}{|c|}{10 -step task } & \multicolumn{2}{|c|}{20 -step task } \\
\hline & $\begin{array}{l}\text { Strong initial } \\
\text { culture }\end{array}$ & $\begin{array}{c}\text { Weak initial } \\
\text { culture }\end{array}$ & $\begin{array}{l}\text { Strong initial } \\
\text { culture }\end{array}$ & $\begin{array}{l}\text { Weak initial } \\
\text { culture }\end{array}$ \\
\hline $\begin{array}{l}\text { Low intrinsic } \\
\text { communication } \\
\text { richness }\end{array}$ & $\begin{array}{l}0.0469 \\
(0.002)\end{array}$ & $\begin{array}{c}0.0242 \\
(0.0011)\end{array}$ & $\begin{array}{c}0.0474 \\
(0.0019)\end{array}$ & $\begin{array}{c}0.0242 \\
(0.0010)\end{array}$ \\
\hline \multirow{2}{*}{$\begin{array}{l}\text { High intrinsic } \\
\text { communication } \\
\text { richness }\end{array}$} & $\begin{array}{c}0.7340 \\
(0.0824)\end{array}$ & $\begin{array}{c}0.5410 \\
(0.0664)\end{array}$ & $\begin{array}{l}0.7419 \\
(0.077)\end{array}$ & $\begin{array}{c}0.5684 \\
(0.0988)\end{array}$ \\
\hline & \multicolumn{2}{|c|}{ 30-step task } & \multicolumn{2}{|c|}{ 40-step task } \\
\hline $\begin{array}{l}\text { Low intrinsic } \\
\text { communication } \\
\text { richness }\end{array}$ & $\begin{array}{l}0.0471 \\
(0.002)\end{array}$ & $\begin{array}{c}0.0241 \\
(0.0012)\end{array}$ & $\begin{array}{c}0.0472 \\
(0.0018)\end{array}$ & $\begin{array}{c}0.0239 \\
(0.0009)\end{array}$ \\
\hline $\begin{array}{l}\text { High intrinsic } \\
\text { communication } \\
\text { richness }\end{array}$ & $\begin{array}{c}0.7188 \\
(0.0724)\end{array}$ & $\begin{array}{c}0.5496 \\
(0.0823)\end{array}$ & $\begin{array}{c}0.7311 \\
(0.0695)\end{array}$ & $\begin{array}{c}0.5215 \\
(0.0914)\end{array}$ \\
\hline
\end{tabular}

Mean over the last 60 data points, std. deviation in parentheses, $N=30$ replications.

Table 3. Overall organizational communication richness for the 16 experimental conditions.

\begin{tabular}{|c|c|c|c|c|}
\hline & \multicolumn{2}{|c|}{ 10-step task } & \multicolumn{2}{|c|}{ 20-step task } \\
\hline & $\begin{array}{l}\text { Strong initial } \\
\text { culture }\end{array}$ & $\begin{array}{c}\text { Weak initial } \\
\text { culture }\end{array}$ & $\begin{array}{l}\text { Strong initial } \\
\text { culture }\end{array}$ & $\begin{array}{c}\text { Weak initial } \\
\text { culture }\end{array}$ \\
\hline $\begin{array}{l}\text { Low intrinsic } \\
\text { communication } \\
\text { richness }\end{array}$ & $\begin{array}{c}0.8528 \\
(0.02)\end{array}$ & $\begin{array}{c}0.5915 \\
(0.0372)\end{array}$ & $\begin{array}{c}0.8556 \\
(0.0158)\end{array}$ & $\begin{array}{c}0.5853 \\
(0.0286)\end{array}$ \\
\hline \multirow{2}{*}{$\begin{array}{l}\text { High intrinsic } \\
\text { communication } \\
\text { richness }\end{array}$} & $\begin{array}{c}0.9881 \\
(0.0003)\end{array}$ & $\begin{array}{c}0.9767 \\
(0.0013)\end{array}$ & $\begin{array}{c}0.9889 \\
(0.0003)\end{array}$ & $\begin{array}{c}0.9791 \\
(0.0009)\end{array}$ \\
\hline & \multicolumn{2}{|c|}{30 -step task } & \multicolumn{2}{|c|}{40 -step task } \\
\hline $\begin{array}{l}\text { Low intrinsic } \\
\text { communication } \\
\text { richness }\end{array}$ & $\begin{array}{l}0.8482 \\
(0.017)\end{array}$ & $\begin{array}{c}0.5780 \\
(0.0323)\end{array}$ & $\begin{array}{l}0.8476 \\
(0.018)\end{array}$ & $\begin{array}{l}0.5792 \\
(0.026)\end{array}$ \\
\hline $\begin{array}{l}\text { High intrinsic } \\
\text { communication } \\
\text { richness }\end{array}$ & $\begin{array}{c}0.9890 \\
(0.0002)\end{array}$ & $\begin{array}{c}0.9798 \\
(0.0008)\end{array}$ & $\begin{array}{c}0.9889 \\
(0.0002)\end{array}$ & $\begin{array}{c}0.9799 \\
(0.0008)\end{array}$ \\
\hline
\end{tabular}

Mean over the last 60 data points, std. deviation in parentheses, $N=30$ replications.

a graph that helps analyze the results of Tables 2 and 3. This graph shows that a higher communication richness at equilibrium is associated with a higher organizational culture strength. The relationship depicted is non-linear and has almost identical shapes for 10, 20, 30 and 40-step tasks. 


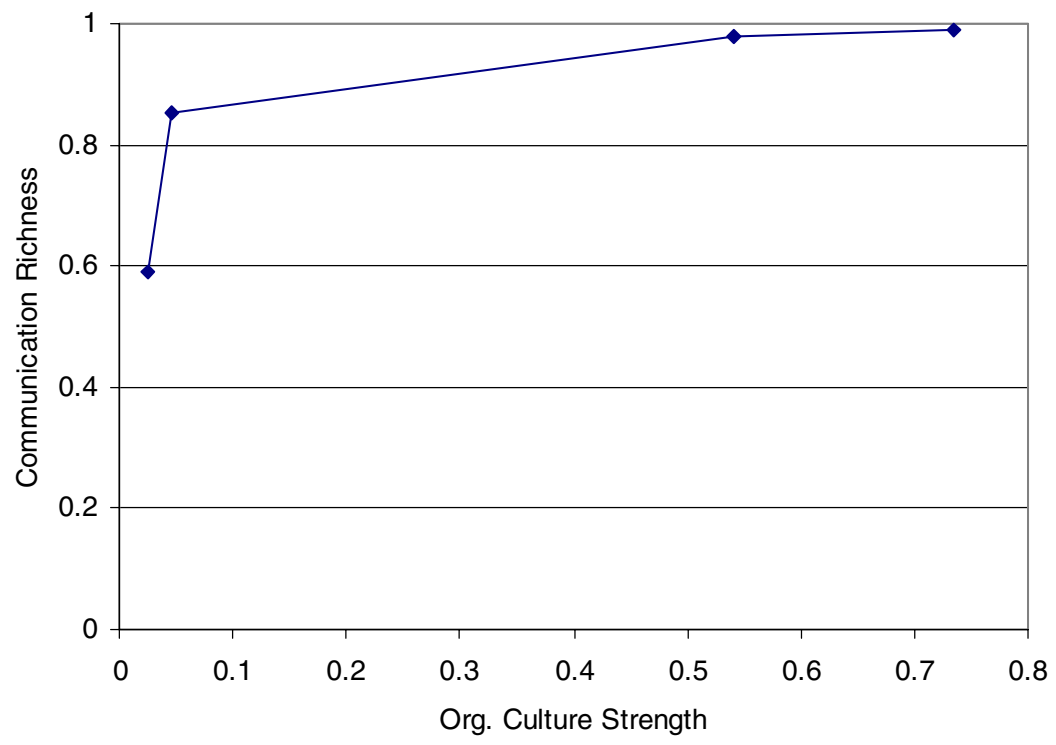

(values shown correspond to figures of Tables 2 and 3 for the 10-step task)

Figure 1. Communication richness vs. organizational culture strength at equilibrium for a 10-step task.

Since the relationship is non-linear, it doesn't make sense to compute a correlation for statistically testing the hypothesis. However, one can compute $t$-tests to verify whether there are statistically significant differences in the mean communication richness, e.g., between pairs of the four final values of cultural strength. Table 4 presents these differences for the 10-step task, comparing strongest to moderate strength, moderate to weak, and weak to weakest. All of them are significant at least at the 0.0001 level. For the 20, 30 and 40step tasks the differences are very similar and also statistically significant. Thus, one can conclude that hypothesis $\mathrm{H} 1$ is supported.

Table 4. Pairwise differences in means of communication richness for different values of organizational culture strength for the 10-step task.

\begin{tabular}{lccc}
\hline & $\begin{array}{c}\text { Final culture } \\
\text { strength }\end{array}$ & $\begin{array}{c}\text { Comm. } \\
\text { richness }\end{array}$ & $\begin{array}{c}\text { Difference in } \\
\text { comm. rich. }\end{array}$ \\
\hline Strongest final culture & 0.7340 & 0.9881 & \\
Moderately strong final culture & 0.5410 & 0.9767 & 0.0114 \\
Weak final culture & 0.0469 & 0.8528 & 0.1239 \\
Weakest final culture & 0.0242 & 0.5915 & 0.2613 \\
\hline
\end{tabular}

All differences significant at least at the 0.0001 level.

For example: strongest - moderate strength $=0.9881-0.9767=0.0114$. 
Table 5. Differences in means of organizational culture strength between high and low intrinsic communication richness.

\begin{tabular}{lcc}
\hline & Strong initial culture & Weak initial culture \\
\hline 10-step task & 0.6871 & 0.5168 \\
20-step task & 0.6945 & 0.5442 \\
30-step task & 0.6717 & 0.5255 \\
40-step task & 0.6839 & 0.4976 \\
\hline
\end{tabular}

All differences significant at least at the 0.0001 level.

The figures show organizational culture strength for high communication richness minus the one for low richness. For example: for a 10-step task: $0.6871=0.7340-0.0469$ (see figures in Table 2).

H2. The richer the communication system used in an organization, all other factors being equal, the stronger the organizational culture will be.

If hypothesis $\mathrm{H} 2$ holds, then the differences between the means of the organizational culture strengths for high and low intrinsic communication richness under the different conditions (see Table 2) should be positive. Table 5 shows the differences between the means of the organizational culture strengths for high and low intrinsic communication richness under the different conditions. These differences were calculated using the figures presented in Table 2. The $p$-values corresponding to the t-tests calculated to assess the statistical significance of such differences in means indicated that all of them were significant at least at the 0.0001 level.

As one can see from the positive differences in means of organizational culture strength, hypothesis $\mathrm{H} 2$ is supported. Both for weak and strong initial cultures, the model ended up with a stronger culture when the communication was richer.

H3. The stronger the initial organizational culture, the faster the culture will stabilize.

To test hypothesis $\mathrm{H} 3$ we first computed the time steps required for the mean of the organizational average culture (OAC) computed over each experimental condition to reach equilibrium. Equilibrium is defined as starting when the time series of organizational average culture remained unchanged. Table 6 presents these figures.

If hypothesis $\mathrm{H} 3$ is true, we would expect that the differences between the times corresponding to an initially weak and strong culture should be positive and significant. Table 7 presents these differences.

Table 7 shows that for low intrinsic communication richness, hypothesis H3 is consistently supported (all differences are positive and statistically significant), whereas for high intrinsic communication richness it is not (differences are relatively small and some are nonsignificant). Figure 2 shows the stabilization times for initially strong and weak cultures and for low and high intrinsic communication richness for a 10-step task. Note that the decrease in stabilization time between an initially weak and strong culture is much more pronounced for low intrinsic communication richness than for a high one. Similar situations occur for tasks involving more steps. This happens because a low intrinsic communication richness prevents some cultural dimensions from changing. Thus, if these unchanged dimensions are 
Table 6. Mean stabilization time for organizational culture for the 16 experimental conditions.

\begin{tabular}{lccccc}
\hline & \multicolumn{2}{c}{10 -step task } & & \multicolumn{2}{c}{ 20-step task } \\
\cline { 2 - 3 } \cline { 5 - 6 } & $\begin{array}{c}\text { Strong initial } \\
\text { culture }\end{array}$ & $\begin{array}{c}\text { Weak initial } \\
\text { culture }\end{array}$ & & $\begin{array}{c}\text { Strong initial } \\
\text { culture }\end{array}$ & $\begin{array}{c}\text { Weak initial } \\
\text { culture }\end{array}$ \\
\hline $\begin{array}{c}\text { Low intrinsic } \\
\text { communication } \\
\text { richness }\end{array}$ & $24.0(3.84)$ & $47.1(18.71)$ & & $18.6(4.69)$ & $33.8(18.24)$ \\
$\begin{array}{l}\text { High intrinsic } \\
\text { communication } \\
\text { richness }\end{array}$ & $23.1(7.67)$ & $30.7(7.38)$ & & $18.2(2.84)$ & $20.4(3.57)$ \\
$\begin{array}{l}\text { Low intrinsic } \\
\text { communication } \\
\text { richness }\end{array}$ & $20.5(5.44)$ & $32.4(10.38)$ & & $20.5(4.93)$ & $34.3(11.27)$ \\
$\begin{array}{l}\text { High intrinsic } \\
\text { communication } \\
\text { richness }\end{array}$ & $18.0(4.27)$ & $19.3(2.85)$ & & $18.0(4.48)$ & $19.3(3.92)$ \\
\hline
\end{tabular}

Standard deviation in parentheses, $N=30$.

Table 7. Differences in stabilization time of organizational culture between initially strong and weak cultures.

\begin{tabular}{lcc}
\hline & Low intrinsic comm. richness & High intrinsic comm. richness \\
\hline 10-step task & $23.10(\ll 0.00001)$ & $7.60(0.00025)$ \\
20-step task & $15.23(0.0001)$ & $2.27(0.009)$ \\
30-step task & $11.83(\ll 0.00001)$ & $1.27(0.183)$ \\
40-step task & $13.80(\ll 0.00001)$ & $1.30(0.237)$ \\
\hline
\end{tabular}

$p$-values in parentheses.

The figures show the difference in stabilization time between an initially weak and strong culture: stabilization time for initially weak culture-stabilization time for initially strong culture. For example: for a 10-step task: $23.1=47.1-24.0$ (see figures in Table 6).

initially similar, as when an initially strong culture exists, then the extrinsic communication richness among agents will be always higher than when these unchanged dimensions are initially dissimilar, as when an initially weak culture exists. Since extrinsic communication richness dictates how much the culture between agents will homogenize per time step, the higher the extrinsic richness, the faster the culture will homogenize. Hence, the impact of an initially strong or weak culture on stabilization time of the culture will be higher when intrinsic communication richness is low than when it is high.

H4. The stronger the organizational culture, the shorter the task-completion time.

Table 8 presents the means and standard deviations of the task-completion times for the entire organization (ATCTO) for the sixteen experimental conditions. These means were 
Table 8. Task-completion time for the 16 experimental conditions.

\begin{tabular}{|c|c|c|c|c|}
\hline & \multicolumn{2}{|c|}{ 10-step task } & \multicolumn{2}{|c|}{20 -step task } \\
\hline & $\begin{array}{l}\text { Strong initial } \\
\text { culture }\end{array}$ & $\begin{array}{c}\text { Weak initial } \\
\text { culture }\end{array}$ & $\begin{array}{l}\text { Strong initial } \\
\text { culture }\end{array}$ & $\begin{array}{c}\text { Weak initial } \\
\text { culture }\end{array}$ \\
\hline $\begin{array}{l}\text { Low intrinsic } \\
\text { communication } \\
\text { richness }\end{array}$ & $\begin{array}{l}19.853 \\
(2.014)\end{array}$ & $\begin{array}{l}33.456 \\
(3.296)\end{array}$ & $\begin{array}{l}20.616 \\
(1.704)\end{array}$ & $\begin{array}{l}41.004 \\
(5.127)\end{array}$ \\
\hline \multirow{2}{*}{$\begin{array}{l}\text { High intrinsic } \\
\text { communication } \\
\text { richness }\end{array}$} & $\begin{array}{l}13.897 \\
(0.073)\end{array}$ & $\begin{array}{l}13.956 \\
(0.105)\end{array}$ & $\begin{array}{l}14.816 \\
(0.071)\end{array}$ & $\begin{array}{l}14.890 \\
(0.072)\end{array}$ \\
\hline & \multicolumn{2}{|c|}{ 30-step task } & \multicolumn{2}{|c|}{40 -step task } \\
\hline $\begin{array}{l}\text { Low intrinsic } \\
\text { communication } \\
\text { richness }\end{array}$ & $\begin{array}{l}22.118 \\
(1.901)\end{array}$ & $\begin{array}{l}50.030 \\
(9.211)\end{array}$ & $\begin{array}{l}23.054 \\
(2.307)\end{array}$ & $\begin{array}{c}61.406 \\
(12.221)\end{array}$ \\
\hline $\begin{array}{l}\text { High intrinsic } \\
\text { communication } \\
\text { richness }\end{array}$ & $\begin{array}{l}15.926 \\
(0.065)\end{array}$ & $\begin{array}{l}15.956 \\
(0.052)\end{array}$ & $\begin{array}{l}16.894 \\
(0.059)\end{array}$ & $\begin{array}{l}16.947 \\
(0.068)\end{array}$ \\
\hline
\end{tabular}

Mean over the last 60 data points, std. deviation in parentheses, $N=30$ replications.

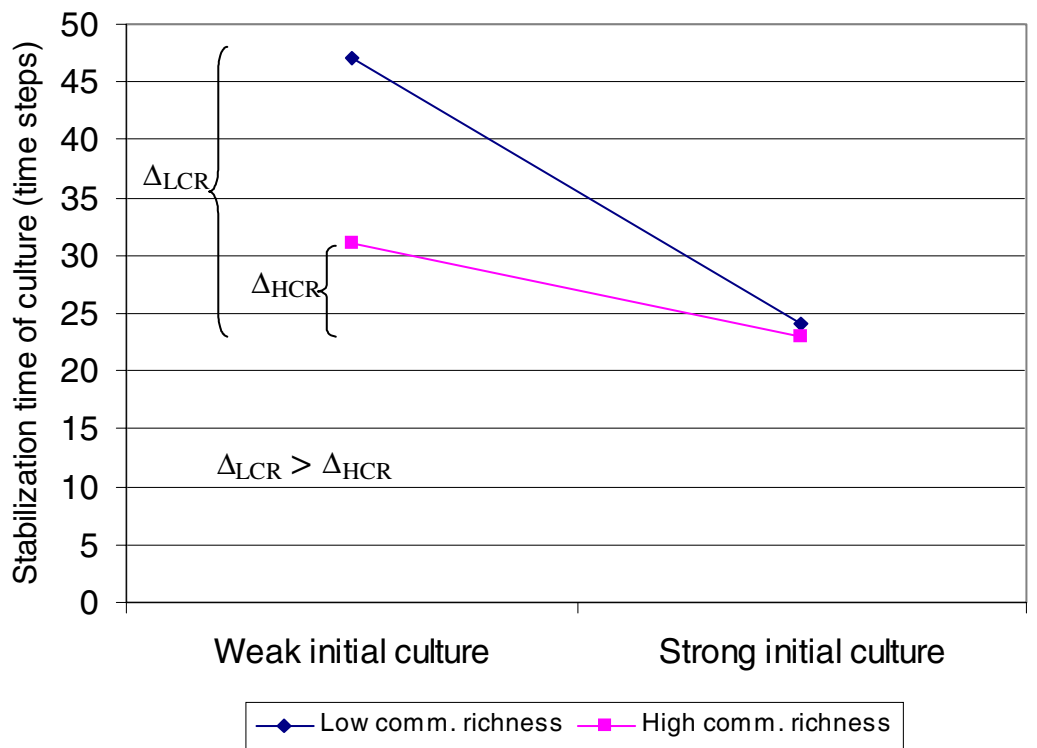

Figure 2. Organizational culture stabilization time for a 10-step task.

calculated using the last sixty data points over the thirty replications of each condition, where the time series were in equilibrium.

If hypothesis $\mathrm{H} 4$ is true, then we should see that the task-completion times for strong final cultures (situations where OOCS is high in Table 2) would be shorter than the ones for 
Table 9. Pairwise differences in means of task-completion times for different values of organizational culture strength for the 10-step task.

\begin{tabular}{lccc}
\hline & $\begin{array}{c}\text { Final culture } \\
\text { strength }\end{array}$ & $\begin{array}{c}\text { Time to complete } \\
\text { tasks }\end{array}$ & $\begin{array}{c}\text { Difference in } \\
\text { task-completion time }\end{array}$ \\
\hline Strongest final culture & 0.7340 & 13.897 & \\
Moderately strong final culture & 0.5410 & 13.956 & -0.059 \\
Weak final culture & 0.0469 & 19.853 & -5.897 \\
Weakest final culture & 0.0242 & 33.456 & -13.603 \\
\hline
\end{tabular}

All differences significant at least at the 0.001 level.

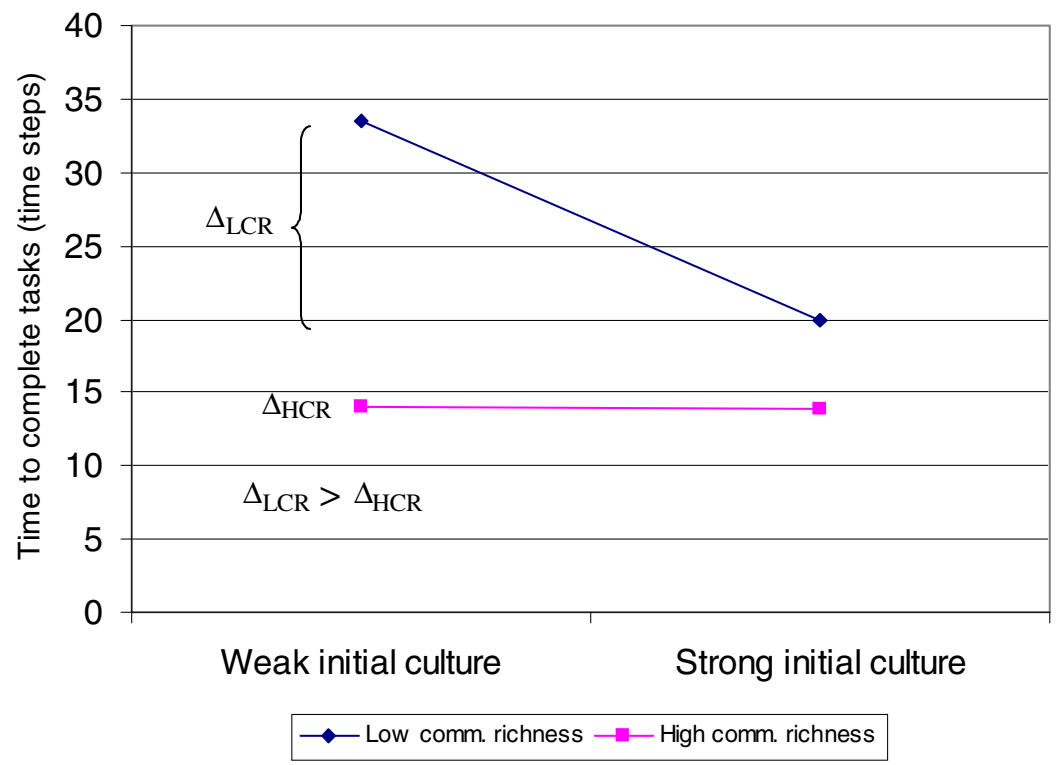

Figure 3. Task-completion time for a 10-step task.

relatively weak final cultures. To assess that, we computed the difference in task-completion time at equilibrium for strong and weak final cultures, using the times of Table 8. Table 9 presents these differences for a 10-step task. All the differences between these times are statistically significant at least at the 0.001 level. One can see that the task-completion times are shorter for strong cultures than for weak ones. This also happens for 20, 30 and 40-step tasks. Thus, hypothesis H4 is supported.

Figure 3 shows a graph of these times for a 10-step task. The impact of an initially strong or weak culture is more pronounced for low intrinsic communication richness than for a high one. Similar results occur for tasks involving more steps. This interaction effect of communication richness on the relationship between culture and task-completion time occurs because a low intrinsic communication richness prevents some of the cultural dimensions from homogenizing. Under that condition, the initial similarity of the dimensions that an initially strong culture produces is more important than when a high intrinsic 
Table 10. Differences in task-completion times between high and low intrinsic communication richness.

\begin{tabular}{lcc}
\hline & Strong initial culture & Weak initial culture \\
\hline 10-step task & -5.96 & -19.50 \\
20 -step task & -5.80 & -26.11 \\
30 -step task & -6.19 & -34.07 \\
40 -step task & -6.16 & -44.46 \\
\hline
\end{tabular}

All differences significant at least at the 0.0001 level.

The figures show the difference in task-completion times between high and low intrinsic communication richness: task-completion time high comm. rich.- taskcompletion time low comm. rich. For example for a 10-step task: $-5.96=13.897-$ 19.853 (see figures in Table 8).

communication richness exists. In this latter case, almost all of the cultural dimensions will eventually homogenize and this will decrease the impact of an initially weak culture on task-completion time at equilibrium.

H5. The higher the communication richness, the shorter the task-completion time.

If hypothesis $\mathrm{H} 5$ holds, we should see in Table 8 that the task-completion times corresponding to a high intrinsic communication richness are smaller than the ones for low intrinsic communication richness. Table 10 presents the corresponding differences, which are statistically significant ( $p$-values $\ll 0.0001)$. Thus, hypothesis $\mathrm{H} 5$ is supported.

\subsection{Effect of an Abrupt Change in the Task Steps on the Dynamics of Task-Completion Time}

In addition to allowing the postulated hypotheses to be tested, the runs showed another interesting aspect of the system's behavior. In one of the runs, task-completion time exhibited a different dynamic from the rest of the runs. In general, task-completion time increases at the beginning of the simulation reaching a maximum and then it begins to asymptotically decrease toward a lower equilibrium value. This happens because the first completed tasks among all the tasks that the organization assigns are the ones that take agents a shorter time to complete. Since those short tasks are the ones the model includes in the first calculations of the mean task-completion time, that figure remains low. Although the short tasks involve the same number of steps as the rest, they take a shorter time to complete because they are easier to accomplish than the rest. Generally, these easy-to-accomplish tasks entail a large number of non-sequential steps that the agents can carry out in parallel and steps that agents can complete by themselves without having to communicate with other agents. As time advances, agents complete the more complicated tasks, which increases the mean task-completion time. However, at the same time, the organizational culture begins to homogenize, making it easier for agents to understand each other. This shortens the task-completion times, which in turn, decreases the mean value of that variable. Finally, the culture homogenizes as much as the conditions allow and the system reaches 
equilibrium. At this stage, the task-completion time reaches its equilibrium value, with additional fluctuations due to the random processes involved.

However, in one run, the dynamics of task-completion time changed. At the time when that variable was reaching its equilibrium value, suddenly it jumped to a higher value, interrupting its asymptotic decrease. After that abrupt variation, the dynamic of task-completion time went back to normal. It began to decrease reaching an equilibrium value. Examining the run, we found that the organization had assigned tasks to agents involving almost no change in the identity and sequence of contacts, from the beginning of the run until the moment the change in dynamics occurred. At that moment, the organization (by chance) drastically changed the identity of the agents involved in each step of the tasks and somewhat the sequence of contacts. Examining the culture of the agents, we saw that because the tasks were initially so stable, the agents had fine-tuned their culture to accomplish such tasks, creating very strong local cultures. These local cultures significantly differed from one another. Thus, when the organization changed the contacts for completing the tasks, the agents had to communicate outside these local cultures. Since these cultures were strong but different, agents could not immediately adjust to their new communication partners. This caused an increase in task-completion time. Eventually, as the local cultures homogenized, that measure improved.

\section{Discussion}

As one can see from the results of the virtual experiments, in general the postulated hypotheses were supported. This is not surprising since the model embeds part of the corresponding theory that supports such hypotheses. However, the interaction effects discovered were not postulated a priori based on the theoretical background. Although a close examination of the model helped explain why these interaction effects occurred, they were discovered because of building the model, running the experiments and analyzing the results. Our intuition regarding the outcomes of the model was not completely right. For example, we correctly hypothesized that the stronger the initial organizational culture, the faster the culture would stabilize (H3) and that the shorter the task-completion time would be (H4). However, we did not anticipate that the initial strength of the culture would moderate those relationships. Thus, the agent-based model served the purpose of enhancing the understanding of the phenomenon under study. The usefulness of this approach in this study agrees with similar ones reported in other papers (Axelrod, 1997a,b).

The new relationships discovered have some useful implications. First, the results showed that the difference in the stabilization time of a culture between high and low intrinsic communication richness media for an initially strong culture is small. On the other hand, for a weak initial culture, the stabilization time of that culture is significantly shorter for media of high richness than for low ones. This suggests that the use of low richness media, such as CMC, is appropriate for stabilizing a culture when this culture is already strong. However, when the culture is weak, one should use high richness media.

Second, the interaction effect of communication richness on the relationship between task-completion time and the initial strength of a culture suggests that a modest increase in the strength of the culture might significantly increase organizational performance. This 
conclusion is important for virtually collocated work, which involves persons geographically separated working on common tasks. Virtually collocated work might be more effective if these persons share a strong culture. Since virtual collocation uses CMC and this medium has an intrinsic low richness, even a modest increase in cultural strength might prove very beneficial. This result is somewhat supported by the findings of a study that showed that virtual teams working on common tasks had a better performance when they had developed some level of trust among their members, an aspect that is part of a culture (Jarvenpaa et al., 1998). Another study also showed that social interaction in computer-supported collaborative learning is hindered by low richness of the media, which in turn hinders learning (Kreijns et al., 2003). However, that obstacle might be overcome if people share some common initial knowledge of each other (Kreijns et al., 2003). Since organizational culture helps homogenize people's values, norms and beliefs, a strong culture might provide part of that personal knowledge.

Finally, the effect of the abrupt change in the task requirements on the task-completion time indicates that the development of strong local cultures in an organization might be beneficial or detrimental to its performance. If the organization faces a stable environment and unchanged internal conditions, so that the tasks remain stable and involve coordination among approximately the same members, then the development of strong local cultures might be beneficial. However, if the conditions are unstable, the organization should try to discourage the development of such strong local cultures, so that the organization is more able to change its behavior when conditions change. This result is partially supported by a study that investigated how people adapt their communicative strategies according to the richness of the media used to accomplish tasks (Newlands et al., 2003). People need to ground their dialogues (i.e. put exchanged information in a context) for dealing with low richness media. This is reflected in the dialogue structure used in their communicative acts. At the beginning, people don't share a common context, and thus need many communicational acts to get the meaning of the information exchanged with the other party. As people establish a context for their communication, they use a more concise style for exchanging information. In our study, in some sense the same happened when agents from very different local cultures began to communicate. At the beginning, agents issued many clarification messages, but as they began to establish a common ground (their culture became more similar), the communication improved and clarification messages dramatically decreased.

\section{Limitations}

As with any study, the present one has limitations. First, we had to decide which parts of the phenomenon to include in the model and which ones to leave out. One key choice we made was to focus on the communicational aspect of the creation and maintenance of an organizational culture and the impact of culture on performance. Since communication is a key element of organizations for establishing and keeping a culture (Schein, 1985, 1990; Chin et al., 2002), we think that the model captures enough elements of the phenomenon to represent it. In an effort to base our model on solid theoretical ground, we decided to incorporate literature from many sources and representing two main streams of research on communication: IRT and interpretivist studies. Literature reviews suggest that those streams 
capture most of the prevalent ideas on communication (Olson and Olson, 2000; Baltes et al., 2002; Chin et al., 2002; Potter and Balthazard, 2002; Kreijns et al., 2003). Given the vast literature we incorporated in our model, it is not surprising that we ended up with a model containing about thirty-one adjustable parameters. Although that may constitute an advantage of the model, it also represents a drawback, as we will discuss next.

Second, we had to balance the tension between ABM flexibility, provided by many adjustable parameters, and the consequent need to choose parameter values that validly represent the situations being modeled. In dealing with those two contradictory issues (flexibility versus problems of validity), we decided to develop a fully parameterized ABM. Having decided that, we faced the challenge of setting the values for the parameters. Since we had 31 parameters, a full factorial experiment at just two levels would have required testing $2^{31}$ (about $2.1 \times 10^{9}$ ) combinations. Even using only one replication per combination, that would have been practically impossible to do. To reduce the combinations to a manageable number, we first set many parameters that specified the upper and lower bounds of probability distributions to the same value. Thus we eliminated many of the random elements originally built into the model, but leaving intact the mechanism for future use. For example, while the status of each agent is sampled from a triangular probability distribution with adjustable bounds we used the same value for both bounds. Choices like that allowed us to reduce the parameters we would use in conducting analyses to the sixteen ones we presented in Sections 3 and 4. To further reduce the number of parameter values used in the virtual experiments reported here, we conducted some sensitivity analysis to determine the effect of changing key parameter values on the outputs of the model used to draw our conclusions. We performed those analyses comparing the time series of the measures we defined in Section 3.7 under different combinations of values for the parameters. Table 11 summarizes the results of those analyses.

As one can see from the results presented in Table 11, the changes in the outputs we noticed are consistent with the theory that we incorporated in the model. Thus, we felt comfortable with the behavior of the model. Additionally, we observed that the changes in the outputs were roughly proportional to the changes to the values of the parameters. Since the test of the hypotheses involved relative comparisons, we noticed that the values set for the parameters would not significantly affect our conclusions. For example, if we set the number of cultural dimensions to twenty instead of ten (all other things remaining the same), OAC would stabilize twice as slowly, ATCTO would be on average twice as long and OOCS would be twice as low. Thus, these effects would roughly cancel each other out when doing relative comparisons of the same output under the two conditions. For example, Table 12 shows a comparison of ATCTO for ten cultural dimensions (from Table 8) to values for ATCTO for twenty dimensions.

As we can see, the conclusion that a stronger initial organizational culture promotes a shorter task-completion time holds for both 10 cultural dimensions (as already demonstrated in Section 4.4) and also for 20 cultural dimensions (difference of ATCTO for strong initial culture minus ATCTO for weak initial culture $=-23.531$ with $p$-value $=0.000$ ). Therefore, we established values for most parameters we would keep fixed around the mid-range of the values tested. However, we must note that given that we had sixteen parameters to analyze, we almost always used one-at-a-time experiments, changing the values of at most 
Table 11. Values of parameters of the ABM used in screening experiments and in final virtual experiments.

\begin{tabular}{|c|c|c|c|}
\hline Parameter & $\begin{array}{l}\text { Values used in } \\
\text { screening }\end{array}$ & $\begin{array}{l}\text { Results of screening } \\
\text { process }\end{array}$ & $\begin{array}{l}\text { Fixed values used in } \\
\text { virtual experiments }\end{array}$ \\
\hline $\begin{array}{l}\text { Prob. assigning sequential } \\
\text { tasks }\end{array}$ & $0.3,0.6,0.9$ & $\begin{array}{l}\text { The higher the probability, } \\
\text { the longer ATCTO }\end{array}$ & 0.5 \\
\hline $\begin{array}{l}\text { Prob. steps of a task } \\
\text { require intergroup } \\
\text { communication }\end{array}$ & $0.3,0.6,0.9$ & $\begin{array}{l}\text { The higher the probability, } \\
\text { the longer ATCTO and } \\
\text { the faster OAC stabilizes }\end{array}$ & 0.6 \\
\hline $\begin{array}{l}\text { Prob. changing identity/ } \\
\text { sequence of contacts }\end{array}$ & $0.3,0.6,0.9$ & $\begin{array}{l}\text { The higher the probability, } \\
\text { the faster OAC stabilizes }\end{array}$ & 0.5 \\
\hline No. of steps of a task & $10,20,30,40$ & $\begin{array}{l}\text { The fewer steps a task has, } \\
\text { the shorter ATCTO }\end{array}$ & $10,20,30,40$ \\
\hline $\begin{array}{l}\text { No. of steps of a task an } \\
\text { agent can perform per } \\
\text { simulation step }\end{array}$ & $10,20,30,40$ & $\begin{array}{l}\text { The larger the no. of steps } \\
\text { an agent can perform, } \\
\text { the shorter ATCTO }\end{array}$ & $10,20,30,40$ \\
\hline No. of cultural dimensions & 10,20 & $\begin{array}{l}\text { The larger the no. of } \\
\text { cultural dimensions, the } \\
\text { slower OAC stabilizes, } \\
\text { the longer ATCTO, the } \\
\text { lower ACETO, the } \\
\text { lower OOCS }\end{array}$ & 10 \\
\hline Variance of initial culture & $5,10,15$ & $\begin{array}{l}\text { The larger the variance, } \\
\text { the slower OAC } \\
\text { stabilizes, the longer } \\
\text { ATCTO }\end{array}$ & 5,10 \\
\hline $\begin{array}{l}\alpha, \beta \text { values of sigmoid } \\
\text { curve (for calculating } \\
\text { CE) }\end{array}$ & $\begin{array}{l}\alpha=0.1,0.3,0.5,0.7 \\
\beta=3,4,6\end{array}$ & $\begin{array}{l}\text { Non-significant effect on } \\
\text { all outputs }\end{array}$ & $\begin{array}{l}\alpha=0.25 \\
\beta=5.0\end{array}$ \\
\hline $\begin{array}{l}\text { Maximum no. of } \\
\text { clarification messages } \\
\text { sent/ received }\end{array}$ & $0,2,4,6$ & $\begin{array}{l}\text { The larger the no. of } \\
\text { clarification messages, } \\
\text { the shorter ATCTO, the } \\
\text { higher ACETO }\end{array}$ & 3 \\
\hline $\begin{array}{l}\text { Maximum no. of changes } \\
\text { of receivers }\end{array}$ & $0,1,2$ & Same as above & 1 \\
\hline $\begin{array}{l}\text { No. of visible cultural } \\
\text { dimensions between } \\
\text { groups }\end{array}$ & $\begin{array}{l}4,6,8,10 \text { (for } 10 \text { cultural } \\
\text { dimensions) } \\
10,14,18,20 \text { (for } 20 \\
\text { cultural dimensions) }\end{array}$ & $\begin{array}{l}\text { The higher the richness, } \\
\text { the shorter ATCTO, the } \\
\text { higher ACETO, the } \\
\text { higher OCCS and the } \\
\text { faster OAC stabilizes }\end{array}$ & $\begin{array}{l}4 \text { (for low richness) } \\
8 \text { (for high richness) }\end{array}$ \\
\hline $\begin{array}{l}\text { No. of visible cultural } \\
\text { dimensions within } \\
\text { group }\end{array}$ & $\begin{array}{l}4,6,8,10 \text { (for } 10 \text { cultural } \\
\text { dimensions) } \\
10,14,18,20 \text { (for } 20 \\
\text { cultural dimensions) }\end{array}$ & Same as above & $\begin{array}{l}6 \text { (for low richness) } \\
10 \text { (for high richness) }\end{array}$ \\
\hline Status of agents & $1,3,6$ & $\begin{array}{l}\text { Small non-significant } \\
\text { change in outputs }\end{array}$ & 1 \\
\hline No. of groups & $4,8,12$ & Same as above & 8 \\
\hline No. of agents per group & $10,20,30$ & Same as above & 30 \\
\hline $\begin{array}{l}\text { No. of agents authorized } \\
\text { to communicate outside } \\
\text { their group }\end{array}$ & $3,6,9$ & $\begin{array}{l}\text { The larger the no. of } \\
\text { agents, the shorter } \\
\text { ATCTO }\end{array}$ & 3 \\
\hline
\end{tabular}


Table 12. Task-completion time for a 10-step task, low communication richness, 10 and 20 cultural dimensions, strong and weak initial cultures.

\begin{tabular}{|c|c|c|c|c|}
\hline & \multicolumn{2}{|c|}{10 cultural dimensions } & \multicolumn{2}{|c|}{20 cultural dimensions } \\
\hline & $\begin{array}{l}\text { Strong initial } \\
\text { culture }\end{array}$ & $\begin{array}{c}\text { Weak initial } \\
\text { culture }\end{array}$ & $\begin{array}{l}\text { Strong initial } \\
\text { culture }\end{array}$ & $\begin{array}{c}\text { Weak initial } \\
\text { culture }\end{array}$ \\
\hline $\begin{array}{l}\text { Low intrinsic } \\
\text { communication } \\
\text { richness }\end{array}$ & $\begin{array}{l}19.853 \\
(2.014)\end{array}$ & $\begin{array}{l}33.456 \\
(3.296)\end{array}$ & $\begin{array}{l}38.451 \\
(2.374)\end{array}$ & $\begin{array}{l}61.982 \\
(6.102)\end{array}$ \\
\hline
\end{tabular}

Mean over the last 60 data points, std. deviation in parentheses, $N=30$ replications.

two to three parameters at the same time. This restricts the screening process and hinders the possibility of finding interaction effects among parameters. Nevertheless, we found some interaction effects when testing the hypotheses, due to the more in-depth analysis allowed by a more reduced number of parameters.

Finally, we should note that the non-significant effect of the change in values of the parameters $\alpha$ and $\beta$ that we used in the calculation of CE (see Section 3.4) are also expected. The $\beta$ parameter simply adjusts how close $\mathrm{CE}$ will be to one when the absolute difference in culture between sender and receiver is zero. Thus, as long as $\beta$ is sufficiently large (say $\geq 3.0$ ), CE will be close enough to one. Since we used $\beta=5.0$, CE will be 0.993 when the cultural difference is zero. The $\alpha$ parameter adjusts how fast CE drops to zero as the difference in culture increases. The bigger $\alpha$, the faster CE drops as the difference in culture increases. Since we used a mid-range value for $\alpha(0.25)$, a change in it around that value does not alter too much the calculation of CE. Furthermore, since ACETO is calculated as an average of many CE's of many individual tasks, one should expect that the heavy averaging over many CE values would not dramatically alter ACETO when one changes $\alpha$ around the established value.

\section{Future Work}

As we already pointed out, the simulation model has about thirty-one adjustable parameters. From those parameters, only a small subset was used in testing the hypotheses. We have employed some other combinations of values for some of the parameters for conducting other virtual experiments and testing other hypotheses (Canessa, 2002). However, given the size of the parameter space, there are clearly many more combinations to explore. Theory should guide this effort. The combinations of parameters to explore should reflect theoretical questions that researchers have not yet been able to answer or some unsolved puzzles regarding the phenomenon under study. One such question involves a more in-depth analysis of the formation of different cultures in an organization. Since one can easily and frequently probe the state of the model and their agents, one could further analyze the dynamics of the cultural formation process. For example, it would be interesting to see how the status and the communication network of the agents affect the spreading of different dimensions of the culture, both in and across groups. Will the culture of high-status agents spread more rapidly than that of low-status agents and become the predominant culture? Or 
since low-status agents are more numerous than high-status agents, would that difference slow down the spreading of the culture of the high status agents? Is there a ratio of low to high-status agents that will prevent high-status agents from dominating the culture? Those questions have been investigated by the field of social network analysis for many years (Krackhardt and Hanson, 1993), but the difficulty of gathering data at many different points in time has restricted the analysis. Here lies one of the values of ABM: we can use the ABM to screen out hypotheses and guide field work and data gathering efforts.

\section{Conclusion}

Most work on communication media and organizational communication has been conducted using experiments and survey or field research. This study took a different approach to analyzing the bi-directional link between the use of communication media and organizational culture. The present model shows that the relationship between organizational culture and the communication richness of systems may exhibit non-linear relationships and interaction effects. The effects of a strong culture are more beneficial when the communication medium exhibits a low capacity for transferring multiple aspects of the culture than when it has a high capacity for doing so. If the communication medium can transfer a limited number of cues, then the contextual factors provided by a strong culture enhance the common ground among organizational members. This enhanced common ground allows a better communication process and thus may improve the performance of the organization.

Additionally, the results show that a stable network of contacts among agents fosters a high achievement of organizational tasks, but when agents are forced to establish contacts with agents outside the usual network for doing their work, the accomplishment of tasks decreases. These outcomes might have interesting implications for the effective use of $\mathrm{CMC}$, as discussed in Section 5. Given the important role CMC plays in allowing virtually collocated work and enhancing the flow of information among members of an organization (Olson and Olson, 2000), these implications are important to consider when deploying $\mathrm{CMC}$ in an organization.

Finally, the ABM described here contributes to organizational communication research in two other ways. First, the model may be used in future studies to help researchers to pinpoint some questions to be answered and consequently design experiments, surveys or field studies. Since the latter approaches generally cannot be easily repeated, it is very useful to have a means of anticipating the possible areas the researcher should focus on. This permits a better design of experiments, surveys or field work. Second, the translation of some social science theories related to organizational communication that have been stated in words to a very precise operationalization, as required in ABM, helps formalize the theories. This assists in enhancing the mutual understanding among researchers and the transfer and accumulation of knowledge in the field.

\section{References}

Alge, B., C. Wiethof and H. Klein (2003), "When Does the Medium Matter? Knowledge-Building Experiences and Opportunities in Decision-Making Teams," Organizational Behavior \& Human Decision Processes, 91(1), 26-37. 
Anderson, P. (1999), "Complexity Theory and Organization Science," Organization Science, 10(3), 216-232.

Axelrod, R. (1997a), "The Dissemination of Culture: A Model with Local Convergence and Global Polarization," Journal of Conflict Resolution, 41, 203-226.

Axelrod, R. (1997b), "Advancing the Art of Simulation in the Social Sciences," in R. Conte, R. Hegselmann and P. Terna (Eds.), Lecture Notes in Economics and Mathematical Systems: Simulating Social Phenomena, Berlin: Springer-Verlag.

Baltes, B., M. Dickson, M. Sherman, C. Bauer and J. LaGanke (2002), "Computermediated Communication and Group Decision Making: A Meta-Analysis,” Organizational Behavior \& Human Decision Processes, 87(1), $156-179$.

Canessa, E. (2002), “Computer Mediated Communication and Organizational Culture: A Survey-Based Study and Agent Based Simulation Model," Doctoral Dissertation. Rackham Graduate School, University of Michigan.

Chatman, J. (1988), "Matching People and Organizations: Selection and Socialization in Public Accounting Firms," Doctoral Dissertation. University of California, Berkeley.

Chin, K., K. Pun, A. Ho and H. Lau (2002), "A Measurement-Communication-Recognition Framework of Corporate Culture Change: An Empirical Study," Human Factors \& Ergonomics in Manufacturing, 12(4), 365-382.

Clark, H.H. (1996), Using Language. Cambridge University Press, New York.

Cornelius, C. and M. Boos (2003), "Enhancing Mutual Understanding in Synchronous Computer-Mediated Communication by Training: Trade-Offs in Judgmental Tasks," Communication Research, 30(2), 147-177.

Daft, R.L. and R.H. Lengel (1986), "Organizational Information Requirements, Media Richness and Structural Design," Management Science, 32(5), 554-571.

Denison, D. (1990), Corporate Culture and Organizational Effectiveness. John Wiley \& Sons, New York.

Fulk, J. and G. De Sanctis (1995), "Electronic Communication and Changing Organizational Forms," Organization Science, 6(4), 337-349.

Gurbaxani, V. and S. Whang (1991), "The Impact of Information Systems on Organizations and Markets," Communications of the ACM, 34(1), 59-73.

Huber, G. (1982), "Organizational Information Systems: Determinant of their Performance and Behavior," Management Science, 28(2), 138-155.

Huberman, B. and N. Glance (1993), "Evolutionary Games and Computer Simulations," Proceedings of the National Academy of Science, USA, 90, 7716-7718.

Hunt, J.W. (1972), The Restless Organization. Wiley and Sons Australasia Pty. Ltd., Sydney, p. 4.

Jacobsen, C. and R. Bronson (1997), "Computer Simulated Empirical Tests of Social Theory: Lessons from 15 Years' Experience," in R. Conte, R. Hegselmann and P. Terna (Eds.), Lecture Notes in Economics and Mathematical Systems: Simulating Social Phenomena, Berlin, Springer-Verlag.

Jarvenpaa, S., K. Knoll and D. Leidner (1998), "Is Anybody Out There? Antecedents of Trust in Global Virtual Teams," Journal of Management Information Systems, 14(4), 29-64.

Kanungo, S. (1998), "An Empirical Study of Organizational Culture and Network-Based Computer Use," Computers in Human Behavior, 14(1), 79-91.

Kiesler, S. (1986), "The Hidden Message in Computer Networks," Harvard Business Review, 64(1), 46-58.

Krackhardt, D. and J. Hanson (1993), "Informal Networks: The Company Behind the Chart," Harvard Business Review, 71, 104-111.

Kreijns, K., P.A. Kirschner and W. Jochems (2003), "Identifying the Pitfalls for Social Interaction in ComputerSupported Collaborative Learning Environments: A Review of the Research," Computers in Human Behavior, 19(3), 335-353.

Lea, M., T. O'Shea and P. Fung (1995), "Constructing the Networked Organization: Content and Context in the Development of Electronic Communication," Organization Science, 6(4), 462-478.

Lee, A. (1994), "Electronic Mail as a Medium for Rich Communication: An Empirical Investigation Using Hermeneutic Interpretation," MIS Quarterly, 18, 143-157.

Newlands, A., A. Anderson and J. Mullin (2003), "Adapting Communicative Strategies to Computer-Mediated Communication: An Analysis of Task Performance and Dialogue Structure," Applied Cognitive Psychology, 17(3), 325-348.

Ngwenyama, O. and A. Lee (1997), "Communication Richness in Electronic Mail: Critical Social Theory and the Contextuality of Meaning," MIS Quarterly, 21, 145-167.

Olson, G. and J. Olson (2000), “Distance Matters," Human Computer Interaction, 15(2/3), 139-178. 
O'Reilly, C.A. and J. Chatman (1996), "Culture as Social Control: Corporations, Cults, and Commitment," Research in Organizational Behavior, 18, 157-200.

Potter, R.E. and P.A. Balthazard (2002), "Virtual Team Interaction Styles: Assessment and Effects," International Journal of Human-Computer Studies, 56(4), 423-443.

Salancik, G.R. and J. Pfeffer (1974), "The Bases and Uses of Power in Organizational Decision Making," Administrative Sciences Quarterly, 19, 453-473.

Sargent, R. (1988), "A Tutorial on Validation and Verification of Simulation Models," in M. Abrams, P. Haigh and J. Comfort (Eds.), Proceedings of the 1988 Winter Simulation Conference, pp. 33-39.

Schein, E.H. (1985), Organizational Culture and Leadership. Jossey-Bass Inc., San Francisco, California.

Schein, E. (1990), “Organizational Culture,” American Psychologist, 45(2), 109-119.

Smith, A.D. and W.T. Rupp (2002), "Communication and Loyalty Among Knowledge Workers: A Resource of the Firm Theory View," Journal of Knowledge Management, 6(3), 250-261.

Schwartz, D. and E. Jacobson (1977), "Organizational Communication Network Analysis: The Liaison Communication Role," Organizational Behavior and Human Performance, 18(1), 158.

Sproull, L. and S. Kiesler (1986), "Reducing Social Context Cues: The Case of Electronic Mail," Management Science, 32, 1492-1512.

Stinchcombe, A. (1990), Information and Organizations. University of California Press Berkeley and Los Angeles, California.

Thompson, J.D. (1967), Organizations in Action, Social Science Bases of Administrative Theory. McGraw-Hill Book Co., New York.

Valacich, J., B. Mennecke, R. Wachter and B. Wheeler (1994), "Extensions to Media Richness Theory: A Test of the Task-Media Fit Hypothesis," Proceedings of the Twenty-Seventh Annual Hawaii International Conference on System Sciences, pp. 11-20.

Weick, K. (1979), The Social Psychology of Organizing, 2nd edn. McGraw-Hill Inc.

William, E. (1977), "Experimental Comparisons of Face-to-Face and Mediated Communication: A Review," Psychological Bulletin, 84(5).

Zack, M. and J. McKenney (1995), "Social Context and Interaction in Ongoing Computer-Supported Management Groups," Organization Science, 6(4), 394-422.

Enrique C. Canessa has an MBA (1991) and a Ph.D. in Computer Information Systems from the University of Michigan, USA (2002). He also has a degree in Electronics Engineering from the Chilean Naval Polytechnic Academy (1985) and a Certificate in the Study of Complex Systems from the University of Michigan (2001). He currently holds a position as associate professor at the Faculty of Science and Technology of the Universidad "Adolfo Ibáñez", Chile. His area of research focuses on how Information and Communication Technology impacts organizations in various sociological aspects such as organizational culture, organizational design and performance. In his research, he applies agent-based modeling and empirical methods to analyze complex systems. He has published his work in several international conferences, chapters in books and in academic journals.

Rick L. Riolo received a B.Sc. (1972, Chemistry and Molecular Biology) and a Ph.D. (1988, Computer Science) from the University of Michigan. He currently is an Associate Research Scientist and Director of the Computer Lab of the Center for the Study of Complex Systems, University of Michigan. His research includes work on genetic algorithms and genetic programming, as well as projects which use agent-based models to better understand the dynamics of a wide variety complex adaptive systems, including models of the evolution and maintenance of cooperation, land-use and land-cover change at the rural urban edge, the effects of pheotypical plasticity on food webs, and decision making and coalition dynamics in closed regimes. 